\title{
CEDOC E CEIHE: ESPAÇOS DE PRESERVAÇÃO DA MEMÓRIA ESCOLAR \\ DOI: http://dx.doi.org/10.1590/2236-3459/57982
}

\section{CEDOC AND CEIHE: SPACES OF PRESERVATION OF THE SCHOOL MEMORY}

\author{
Eduardo Arriada \\ Universidade Federal de Pelotas, Brasil. \\ Elomar Antonio Callegato Tambara \\ Universidade Federal de Pelotas, Brasil. \\ Vanessa Barrozo Teixeira \\ Universidade Federal do Rio Grande do Sul, Brasil.
}

$\cos 80$

\section{Introdução}

O presente artigo tem como objetivo relatar aspectos do processo de consolidação do Centro de Documentação - Cedoc - parte constitutiva do Centro de Estudos e Investigações em História da Educação - Ceihe -, particularmente sob o ponto de vista do trabalho de constituição de sua identidade visual.

Para além do simples fato de preservação da memória da escolarização centrada nos documentos oficiais - leis, decretos, legislação -, assim como das reformas de ensino, ou do pensamento pedagógico temos o papel, como centro de documentação, de nos preocuparmos com a diversidade de fontes e memórias que podem subsidiar futuras investigações por parte dos historiadores da educação. 
Portanto, não podemos prescindir de estudos e pesquisas que considerem os lugares da memória como capazes de fornecer pistas, indícios, caminhos que possibilitem novas investigações, novos olhares e propiciem, ao mesmo tempo, manter, questionar, revisar os diversos pressupostos teórico-metodológicos das ciências atuais.

Entre diversas preocupações, busca-se formar pesquisadores que investiguem temas em história da educação. No rastro das novas correntes historiográficas, novos objetos, novos problemas e novas abordagens dinamizam nossas práticas. Agora temas como a cultura material escolar, a estrutura interna das escolas, seus programas e currículos, os manuais escolares, os agentes educacionais estão nas nossas análises, assim como os sistemas educacionais.

\section{As fontes: contar os fatos, escrever a história}

O historiador atual sabe que é impossível reconstituir o passado tal qual ele um dia foi. Quando muito podemos recuperar facetas, partes de um todo muito mais complexo, dinâmico e pulsante. Por mais sério, competente, organizado e metódico que seja o pesquisador, as fontes que irá utilizar, em certa dose, já estão pré-estabelecidas, ou seja, no seu longo processo de manutenção e tentativa de preservação, alguns documentos foram mais valorizados que outros, no geral, sobrevivem muito mais documentos de caráter oficial. Essa é uma das razões pela qual, durante muito tempo, os historiadores da educação, realizaram trabalhos que privilegiavam o institucional em detrimento da cultura escolar.

Outros tipos de fontes, indiferente do seu valor intrínseco, muitas vezes são relevantes pela visão de sociedade que o pesquisador carrega. Outro aspecto a salientarse é que certos documentos contam com uma margem de acaso, sorte, imprevisibilidade. Quem não gostaria de ter em mãos cartas particulares de professores do século 19 ou um rico acervo iconográfico retratando a escola, o pátio, a sala de aula, ou ainda, os cadernos escolares dos alunos. Às vezes a sorte ajuda e isso não é só competência. Num país em que as condições de preservação são precárias, no qual as autoridades públicas e privadas muito pouco estão preocupadas, que a população como um todo está relativamente desatentas com o passado, cabe há alguns abnegados, enlouquecidos, fanáticos, a montagem de acervos ricos e essenciais para recontarmos aspectos da nossa educação pretérita. Pois de fato há "uma história da educação ameaçada" (Magalhães, 1996, p. 1).

Sabemos que, por si só, os documentos não falam, nem podemos fetichizar o seu valor. Eles adquirem importância, ou até mesmo um grande valor, pelo ineditismo ou por novos dados que possibilitam um novo olhar. Tudo isso existe, mas acima disso estão às perguntas que iremos formular a esses documentos, que questionamentos, indagações. Devemos procurar aquilo que nem sempre vem explícito. Quem produziu o documento, com que objetivos? Como foi conservado ao longo do tempo? Encontra-se inteiro, fracionado, sofreu modificações, existem variantes? Outros documentos similares podem corroborar o que foi dito ou então negar?

Neste sentido, é que se consolida a missão do Cedoc/Ceihe de constituir-se em um lugar de preservação de fontes que possibilitem a pesquisadores e estudiosos, no presente e no futuro, acesso às mesmas. 
Ceihe: da garimpagem, coleta e preservação à prática da organização, acessibilidade e disponibilidade para a pesquisa

O Centro de Estudos e Investigações em História da Educação, vinculado à Faculdade de Educação da Universidade Federal de Pelotas/RS, foi criado em 2002. Buscava-se reunir um grupo de pesquisadores na área de história da educação. Sua concepção em grande parte esteve norteada pelos debates e abordagens desse campo, onde despontam temas como: história das instituições escolares, cultura escolar, cultura material escolar, impressos estudantis, manuais escolares, cartilhas, memórias de professores.

Em relação à organização e estrutura funcional, o Ceihe subdivide-se em dois setores com atuação relativamente diferenciada, mas estreitamente interligada: um centro de documentação e um centro de pesquisa.

Enquanto centro de pesquisa, o Ceihe tem como objetivos: fomentar a pesquisa historiográfica; desenvolver investigações individuais e coletivas sobre diversos temas no campo historiográfico educacional; proporcionar pesquisas e estudos comparados; produzir trabalhos científicos e divulgá-los em diferentes fóruns; manter sessões de estudos de caráter teórico-metodológico; promover debates e seminários específicos; dar suporte aos alunos durante a fase de preparação de monografias, artigos, dissertações e teses.

Enquanto centro de documentação enfatiza a história da educação, em particular a história da educação da região. Neste sentido, procura recuperar a memória da história da educação regional preservando todo o tipo de material e constituindo acervos documentais temáticos; disponibilizar o acervo documental - fontes impressas, manuscritas e iconográficas; constituir um acervo de dissertações e teses produzidas no campo da história da educação; reconstituir a materialidade das rotinas e do cotidiano escolar: carteiras escolares, mesas, lousas, lápis, canetas, palmatórias, cadernos escolares, manuais escolares; recolher e catalogar materiais doados por instituições ou pessoas; promover exposições e mostras sobre história da educação.

Como Centro de Documentação, o primeiro desafio foi vencer a exiguidade do espaço físico. No entanto, desde 2001 o espaço físico tem sido ampliado e, atualmente, o acervo se constitui de alguns milhares de títulos, de modo especial, manuais e textos escolares. O acervo encontra-se em processo de catalogação e classificação no sistema Winisis, devendo estar disponibilizado em pouco tempo online.

Em relação à cultura material escolar o acervo do centro de documentação disponibiliza ao investigador em história da educação, carteiras escolares, ardósias, coleções de lápis, tinteiros, borradores, cadernos escolares, canetas, penas, estojos, flâmulas, boletins, cadernetas, materiais para as aulas de desenho, entre outros objetos que nos permitem compreender aspectos dessa cultura material.

A partir da conquista de um espaço físico mais adequado para o Centro de Documentação ${ }^{1}$ estabeleceu-se um planejamento estratégico com objetivo de consolidalo em um prazo de cinco anos. Tal procedimento visava concretizar vários aspectos inerentes a um centro com tal natureza, que ainda não possui força de trabalho consentânea a seu múnus como, por exemplo, arquivistas, museólogos, restauradores,

\footnotetext{
${ }^{1}$ Segundo andar do anexo do prédio do Lyceu Rio-grandense, Rua Andrade Neves, 1550-A, Pelotas, RS email: cedoc14@outlook.com. 
encadernadores. Passos importantes foram executados tendo como substrato a análise realizada em dois trabalhos de conclusão de curso que tiveram como objeto a criação da identidade visual do Cedoc e sua identidade de comunicação interna.

Este é um aspecto importante, pois permite dar uma maior visibilidade à instituição e vinculá-la melhor a comunidade, atraindo eventuais doações, associações, recepções de acervos em comodato, etc.

A partir do TCC da aluna do curso de design, Elaine Schaab, desenvolveu-se um sistema de visualização que paulatinamente estamos implantando.

Provisoriamente, o Cedoc estrutura-se da seguinte forma: $1^{\circ}$ ambiente: recepção; secretaria; sala de pesquisa; espaço expositivo. $2^{\circ}$ ambiente: sala de processamento técnico, catalogação; tombamento; higienização; acondicionamento. $3^{\circ}$ ambiente: sala de pesquisadores, acervo. $4^{\circ}$ ambiente: acervos especiais, acervo de estabelecimentos escolares: Escola Santa Margarida; Escola Salis Goulart; CAVG; Colégio Municipal Pelotense. UFPel acervos pessoais: Acervo Krammer, Acervo Tambara Arriada; Acervo Ceres Bonato, Acervo Bento Gonçalves. $5^{\circ}$ ambiente: reserva técnica, recuperação de documentos, setor de digitalização

\section{Pesquisa e comunicação de acervos escolares: o papel desenvolvido pelo Ceihe}

Nesta perspectiva destacam-se três momentos que têm ocorrido de maneira periódica: o Encontro de História da Educação em Debate, a Mostra de História da Educação em Pelotas e a publicação dos dois primeiros guias de fontes do Cedoc ${ }^{2}$.

Nosso trabalho tem privilegiado temáticas específicas da história da educação da região, particularmente de Pelotas. Até o presente momento foram realizadas, entre outras, as seguintes mostras: História da educação em Pelotas (2001), Cartilhas escolares na educação pelotense (2002), Os impressos da Faculdade de Educação (1970-2003) (2003); Almanaques e álbuns na história da educação pelotense (2004); Mostra do bicentenário de Pelotas (2012); Mostra biblio-iconográfica: etnia e educação (2011-12). Esta última ainda foi constituída de quatro exposições de curta duração: os afro-brasileiros, os teuto-brasileiros, os ítalo-brasileiros e os luso-brasileiros. Nesse conjunto de etnias e educação, a mostra teve a preocupação de mostrar impressos, manuais escolares, livros de leitura, cartilhas em alemão, italiano, cartilhas editadas em Portugal e no Brasil, cadernos escolares, atlas, etc. Ao total são mais de dois mil itens, entre obras didáticas e objetos da cultura material escolar.

A exposição é considerada um dos principais meios de comunicar um acervo, sendo responsável por tornar os objetos acessíveis e, ao mesmo tempo, por possibilitar a interação com o público. Planejar e organizar exposições requer, além da pesquisa e dos procedimentos curatoriais, a seleção prévia dos objetos, o que demonstra que as exposições não são neutras, existindo sempre um discurso, uma linguagem que permeia sua concepção e planejamento.

\footnotetext{
${ }^{2}$ ARRIADA, Eduardo; TAMBARA, Elomar; AMARAL, Giana Lange do; WEIDUSCHADT, Patricia. Guia de fontes 1: textos escolares. Pelotas: Ceihe/UFPEL, 2014 e ARRIADA, Eduardo; TAMBARA, Elomar; AMARAL, Giana Lange do; WEIDUSCHADT, Patricia. Guia de fontes 2: etnia afro-brasileira. Pelotas: Ceihe/UFPEL, 2014. 


\section{Considerações finais}

A criação de um centro de estudos e investigações em História da Educação ganhou visibilidade e ênfase ao salientar o trabalho desempenhado não apenas em relação às possibilidades de desenvolvimento de pesquisa mas, também, pelo caráter de preservação, catalogação e divulgação do acervo constituído.

Dessa forma, como centro de documentação e pesquisa engajado com a salvaguarda e a acessibilidade dos acervos escolares, que carregam consigo a história da educação brasileira, temos a missão de continuar dando seguimento aos projetos atuais, bem como implementando novas ideias a fim de consolidar as atividades que vem sendo desenvolvidas e assim, permanecer articulando formas de enfocar a importância de se preservar as memórias educacionais.

\section{Referências}

ARRIADA, Eduardo; TAMBARA, Elomar; TEIXEIRA, Vanessa Barrozo. Acervos escolares: espaço de salvaguarda e preservação do patrimônio histórico-educativo. Revista Didática Sistêmica, Furg, v. 14, n. 2, 2012, p. 15-29.

CASTRO, Renata Brião de Castro. Centro de documentação, documentos, patrimônio: ações educativas voltadas para o patrimônio: o caso do Cedoc - Pelotas/RS. Pelotas, Ufpel, 2014. Monografia (trabalho de conclusão de curso em Museologia). Universidade Federal de Pelotas.

TAMBARA, Elomar. Centro de Estudos e Investigações em História da Educação. In: Horizontes. Bragança Paulista: USF, 2005, p. 141-146.

SCHAAB Elaine. Design de identidade e sinalização para o Centro de Documentação CEIHE UFPel. Monografia (trabalho de conclusão de curso em Design Gráfico). Universidade Federal de Pelotas.

EDUARDO ARRIADA é professor associado da Universidade Federal de Pelotas. É integrante do Ceihe e coordenador do Cedoc

Endereço postal: Rua D. Pedro II, 414 - 96010-300 - Pelotas - RS - Brasil.

E-mail: earriada@hotmail.com.

ELOMAR TAMBARA é professor titular da Universidade Federal de Pelotas e integrante do Ceihe.

Endereço: Caixa postal 628 - 96010-971 - Pelotas - RS - Brasil.

E-mail: tambara@ufpel.tche.br.

VANESSA BARROZO TEIXEIRA é professora assistente do Departamento de Ciências da Informação da Faculdade de Biblioteconomia e Comunicação na Universidade Federal do Rio Grande do Sul.

Endereço: Ramiro Barcelos, 2705 - 90035-007 - Porto Alegre - RS - Brasil.

E-mail: vanessa.barrozo@ufrgs.br.

Recebido em 30 de junho de 2015.

Aceito em 8 de agosto de 2015. 